\title{
Evidence and Speculation: Reimagining Approaches to Architecture and Research within the Paediatric Hospital
}

\author{
Rebecca McLaughlan ${ }^{1}$ and Alan Pert ${ }^{2}$ \\ 1 Melbourne School of Design, Faculty of Architecture, Building and Planning, \\ University of Melbourne, Australia. Orcid ID: 0000-0001-6909-009X \\ 2 Melbourne School of Design, Faculty of Architecture, Building and Planning, \\ University of Melbourne, Australia. Orcid ID: 0000-0002-4952-0571
}

contact for corresponding author:

rebeccca.mclaughlan@unimelb.edu.au

The University of Melbourne

Victoria 3010

Australia

T: +613834 48327

contributorship statement: The case studies discussed within this article were completed within an architectural design studio at the University of Melbourne (Masters of Architecture programme). The idea for the studio was conceived by Pert and taught by Pert and McLaughlan. McLaughlan prepared the manuscript and associated research while Pert provided critical feedback on its development and theoretical positioning.

funding: This research was conducted as part of the project 'Design for Wellbeing: Recognising benefits for patients through best practice hospital design' a collaboration between the University of Melbourne, Faculty of Architecture, Building and Planning, and Lyons architecture. It is funded under an Australian Research Council Linkage Project Grant (no. LP140100202).

acknowledgements: The case study projects were completed by Imogen Siberry and Ding Yu as part of an architectural design studio within the Masters of Architecture programme at the University of Melbourne. The authors wish to thank Siberry and Yu both for their sincere and critical engagement with this important topic and their generosity in allowing this work to be discussed herein. Several people contributed their time to this studio. We extend our thanks to: Professor Corbett Lyon, Stefano Scalzo and Codey Lyon (Lyons Architecture), Professor Julie Bernhardt (Stroke Division, Florey Institute), Jonathan Daley (Studio Huss), Sarah Blaschke (Peter MacCallum Cancer Centre), Dr Pippa Soccio, Stephanie Liddicoat and Ahmed Sadek (University of Melbourne). Finally, the authors would like to thank Reviewer 2 for their insightful critique of the original submission that valuably informed the positioning of this paper. 


\title{
Evidence and Speculation: Reimagining Approaches to Architecture and Research within the Paediatric Hospital
}

\begin{abstract}
As the dominant research paradigm within the construction of contemporary healthcare facilities, Evidence Based Design (EBD) will increasingly impact our expectations of what hospital architecture should be. With a focus on obtaining credible evidence to support design decisions, typical research methods include the analysis of existing and prototyped solutions for the hospital environment. Yet medical care is a rapidly evolving field. Alterations to workforce composition, patient demographics, funding models and available technologies can trigger swift and unpredictable change. To imagine new directions for the design of healthcare facilities requires a model that can project beyond existing constraints, recognising that these may only be temporary. Speculative design employs a design-based research methodology to stimulate innovation by utilising the artefacts created through this process to enable critical reflection on existing practices. This paper examines two architectural propositions for the paediatric hospital created using a speculative design methodology to interrogate the knowledge types currently excluded within EBD. These case studies identify new approaches for the design of contemporary paediatric hospitals and contribute to a broader conversation about the limitations of EBD practice.
\end{abstract}

\section{Note: designer one is Imogen Siberry, designer two is Ding Yu;}

names were removed for blind peer review.

\section{List of Figures}

Figure 1 Entrance garden and tunnel, 'The Fable Hospital', [designer one], 2016.

Figure 2 Entrance carousel, 'Neverland', [designer two], 2016.

Figure 3 A System to Lift the Spirits (the waiting room), section drawing, 'The Fable Hospital', [designer one], 2016.

Figure 4 Surgical space, 3D laser-cut section drawing, 'The Fable Hospital', [designer one], 2016.

Figure 5 Ferris wheel consultation room, 'Neverland', [designer two], 2016. 


\section{Introduction}

Evidence Based Design (EBD) is the field of research that seeks to measure the capacity of the built environment to assist in relieving anxiety among hospital users. This can support the healing process for patients and improve staff performance in ways that correlate positively with patient safety. ${ }^{1}$ Ultimately it seeks the creation of evidence based guidelines for design features and approaches that are capable of meeting these aspirations. However, as Savransky and Rosengarten have pointed out, the research methods and ontological positions that underpin any field determine what kinds of solutions are able to emerge and those whose emergence is precluded. ${ }^{2}$ In addition to prescribing what counts as evidence, and what types of evidence count, disciplinary knowledge is inscribed in 'routines' that are established from 'the shared propositions and collective performance of individuals across contexts and situations over time. ${ }^{3}$ The risk with any research paradigm is that the acceptance of particular methods and ontological positions can act to limit innovation. This paper examines two architectural propositions for the paediatric hospital created using a speculative design methodology: 'The Fable Hospital', by [designer one], and 'Neverland', by [designer two]. These projects highlight the types of knowledge that are currently excluded within EBD and confirm the relevance of this design-based methodology to complement existing research approaches within this field.

\section{Positioning Speculative Design relative to Evidence Based Design}

While Ulrich's 1984 study 'View through a window may influence recovery' is broadly accepted as the formative study within EBD, the Centre for Health Design, a driving force within this field, was not formed until 1993. ${ }^{4}$ Seeking an evidence basis for design, however, has origins reaching back to the environmental psychology studies of the 1960s. With a focus on obtaining credible evidence to support design decisions, typical research methods within EBD include the analysis of existing and prototyped solutions for the hospital environment. Pre- and post-occupancy evaluations are prevalent. Similarly, prototyping is used to test performance or behavioural changes relative to the alteration of environmental variables that may, for example, include paint colours, light levels, furniture or equipment placement. ${ }^{5}$ These studies typically obtain user feedback, observations of spatial use and the behavioural changes associated with these alterations. Studies can include various physiological measures including heart rate, blood pressure, salivary cortisol levels, galvanic skin response and functional Magnetic Resonance Imaging (fMRI). While prototyping is used to test design ideas within the context of $E B D$, funding restrictions makes this less common than interrogating existing (built) solutions. 
If speculative design is a strategy to challenge accepted disciplinary research and design practice then the affordances and limitations of EBD first need to be understood. EBD provides a resource to assist designers in making and justifying decisions within the design process. While this is obviously valuable where credible research exists, how can a designer justify a decision when there is no evidence? Either because the issue at hand has not gained the attention of researchers or because a particular solution has never been built before? There is no evidence, for example, that could be used to create design guidelines for the ideal provision of social spaces within paediatric hospitals. While compelling research exists to suggest that peer support offers therapeutic benefits, the question of what types of spaces would facilitate positive social interaction, or what the optimum size, location, or atmospheric qualities of these spaces would be, has simply not been studied in the context of the hospital. ${ }^{6}$ Furthermore, researchers have cautioned against the translation of findings from other contexts into the far more stressful space of the hospital. ${ }^{7}$ The relative nascence of this field, in conjunction with the tendency for much of the available research to be based on existing facilities, results in several gaps.

Bennis and O'Toole, in reviewing the limitations of evidence based decision making within management, have cautioned that where evidence is incomplete professionals are liable to 'overweight' the value of the knowledge that is available. ${ }^{8}$ The multiple versus single occupancy room debate in EBD confirms that Bennis and O'Toole's observation is equally applicable to this field. Hospitals constructed over the last decade have included increasing percentages of single rooms as these have been perceived to support improvements to patient care. ${ }^{9}$ Yet two recent studies, both employing more comprehensive, mixed methods approaches than previous studies, reveal previously unrecognized drawbacks associated with this model. ${ }^{10}$ Adopting inconclusive evidence on the promise of a possible benefit stretches the justification for evidence based practice. This opens the discussion to research that questions whether evidence based decision making is, in fact, more valuable than intuitive decision making and whether different contexts could benefit from different decision making models. ${ }^{11}$

The risk of incomplete evidence being over weighted within EBD may be more pronounced owing to the economic pressures that surround hospital construction. The direct physiological benefits for patients that EBD seeks to locate are underpinned by a need to decrease healthcare costs in respect of an ageing population (with the ramifications of an ageing workforce) and increasing rates of illnesses such as obesity, diabetes and depression. ${ }^{12}$ While paediatric hospitals are subjected to less of this pressure than adult facilities they are certainly not immune to it. Hospital administrators are increasingly expected to base construction decisions on evidence and, preferably, the kind that might secure a reduction in operating costs. Ulrich's 1984 study offered the promise that design may be able to assist in maximising staff 
efficiency, reducing lengths of stay and/or the use of sedative or analgesic medications. ${ }^{13}$ Becker, Sweeny and Parsons have observed that there must be a 'tipping point' whereby the constant improvement of healthcare environments no longer results in benefits sufficient to justify the costs incurred. Their question of 'how much smaller or less attractive a facility could be while generating similar [therapeutic] results ${ }^{14}$ is revealing of the economic imperative that underpins this field and adds to the challenge of stimulating innovation.

While EBD is largely limited to investigations of built solutions, or locating funding to prototype new solutions, speculative design offers a complementary research method. By allowing the theoretical exploration of solutions that challenge accepted social, cultural, technical or economic values, this method can stimulate innovation by provoking questions that might otherwise never be asked. ${ }^{15}$ Dunne and Raby have argued that design too often reinforces the status quo without questioning the necessity or ramifications of contemporary design practice. ${ }^{16}$ DiSalvo has suggested that the artefacts arising from a speculative design methodology should encourage the audience to ask themselves 'why the values embodied in the proposal seem "fictional" or "unreal" and to question the social and cultural mechanisms that define [those values]. ${ }^{17}$ Savransky and Rosengarten posited a similar question when they argued for a greater appreciation of 'speculative dreaming' in biomedical research based on its ability to 'think alongside other situations, practices and experiences that prevailing regimes of evidence would deem improbable, artefactual or confounding.' Furthermore that such an approach could be used to 'transform the horizon of possibilities.' $^{18}$

As a form of design research, speculative design 'exploits the design process' in order to advance understanding. ${ }^{19}$ It includes the identification of a design problem that responds to a goal, need or opportunity, that addresses the 'challenges, constraints and opportunities presented by the design context', that is then responded to through 'iterative cycles of design and implementation, using each implementation as an opportunity to collect data to inform subsequent design. ${ }^{.0}$ Implementation refers to prototyping a solution. This may comprise a physical prototype or, according to contemporary notions of prototyping put forward by Burnett and Evans, refer to the process of making public an idea in one format or another (be that sending a resume, publishing a blog post or giving a presentation). This latter form of prototyping enables the maker to test how others relate to the design solution proposed and use this information to inform subsequent moves. ${ }^{21}$ Edelson suggests that design research can provide a useful complement to traditional research methods because it has the capacity to 'yield new theories ... for resolving important problems ... theories that could not be generated either by isolated analysis or traditional empirical approaches. $^{22}$ 
A risk of evidence based decision making, across disciplinary fields, is that it can be largely self-referential. Each research paradigm sets up its own value system, determined by the methods and approaches that are deemed to be rigorous and trustworthy. ${ }^{23}$ Martin and Dunne have observed that this can lead to a situation where problems are assumed to be both recognisable and solvable through the application of existing methods, and that a depth of disciplinary expertise will be sufficient to solve a problem, instead of drawing on expertise from across disciplines. ${ }^{24}$ While it must be acknowledge that EBD is well positioned to draw on understandings from medicine, architecture and environmental psychology, this may not be sufficient to overcome the risk of self-referentialism. If designers are consistently focused on research conducted in existing hospitals to inform their design approach to new hospitals then innovation will always be subject to a degree of limitation. As a design based methodology, speculation is underpinned by design thinking which, as Dunne and Martin point out, places a high value on problem solving through interdisciplinary engagement. ${ }^{25}$

Speculative projects provide only the briefest semblance of professional practice. They are free from the difficulties of budgets, briefing, contract negotiations, construction programmes and compromises that are involved in the delivery of complex hospital facilities. While the authors make no suggestion that these considerations are unimportant, there may be value in their temporary suspension. This act of suspension aligns speculative design more closely with the concept of blue sky research that is justified by the unanticipated breakthroughs it can potentiate. Professor Mark Walport, former director of the Wellcome Trust, has pointed out that significant advances in genetics and stem cell biology have 'emerged from teams who had no idea where their work would lead. ${ }^{26}$ The Maggie's Centres could be conceived of as a product of blue sky (or speculative) thinking. Forming a network of buildings across the UK, these twenty-two centres provide information, advice and psychological support to cancer patients. ${ }^{27}$ They were the brainchild of the late Maggie Keswick Jencks who, as an oncology patient, identified a social and psychological need relative to the delivery of oncology care and asked the question 'what if?' What if architecture could show empathy, calm anxieties, raise spirits, help you to 'read yourself differently,' acknowledge and rise to a difficult challenge with you? ${ }^{28}$ Jenck's enlisted a group of eminent architects to seek solutions to these questions and, in doing so, recast expectations about what an appropriate atmospheric quality of a hospital interior could be. While the Maggie's Centres contain no clinical functions, their influence can now be traced through facilities that include clinical and research functions. The recently completed Victorian Comprehensive Cancer Centre (Melbourne, Australia) is a key example of a complex clinical facility that has adopted lessons from the architectural atmosphere, patient-centred values and broader social functions advocated by the Maggie's Centre model. ${ }^{29}$ This provides 
inspiration for just how far blue sky thinking could take us with respect to questions of architecture and wellbeing.

\section{Paediatric Hospitals and the Suspension of Disbelief: On Entrances, Waiting Rooms and Procedure Spaces}

Research has found that paediatric surgical patients who experience high levels of preoperative anxiety suffer more pain during postoperative recovery. ${ }^{30}$ This suggests that pre-service spaces such as entrances and waiting rooms may play an important role in patient wellbeing. In contemporary hospital construction, much effort is directed to the design of these spaces. It should be acknowledged, however, that this partially driven by the fact that entrances and waiting spaces are light on the demands of technology, necessary efficiencies of movement and concerns of infection control. In short, these spaces are less restrictive architecturally. This section will introduce two case studies created for the paediatric hospital context using a speculative design methodology. 'The Fable Hospital' by [designer 1] and 'Neverland'31 by [designer 2] suggest benefits from expanding perceptions of what the experience of entrance and waiting spaces could be, while imploring us to engage further with the architectural potential for procedural spaces within the hospital. More importantly, these architectural speculations raise questions regarding the types of evidence that are excluded from EBD, particularly knowledge from other disciplines. They highlight that greater interdisciplinarity could offer new directions for answering complex questions in paediatric healthcare, particularly with regard to children suffering from chronic illnesses.

[designer one's] choice of title was an ironic play on the Fable Hospital concept that emerged within the field of EBD in 2004 and was conceived of as:

an imaginary amalgam of the best design innovations that had been implemented and measured by leading organisations [and] an early attempt to analyse the economic impact of designing and building an optimal hospital facility... [it sought to illustrate that] carefully selected design innovations ... could [over time] ... reduce operating costs and increase revenues. ${ }^{32}$

[designer one's] work could not have been positioned further from these aspirations; she used the term fable in its literal sense, to refer to a hospital that one might experience in a similar way to a work of fiction. [designer one] made the connection between a child's journey into an unfamiliar hospital and 'Alice falling down the rabbit hole and ending up in Wonderland or Wendy flying with Peter to Neverland.' Further she identified an overlap between the world of immersive video gaming and the worlds created by fiction. Videogames require players to 'freely interact with a complex environment and test the boundaries of their imagination. To progress 
children are expected to solve problems and gain wisdom much like the story arcs of fiction.' [designer one's] proposition therefore asked 'what can the paediatric hospital learn from the protagonists of classic children's stories and their journeys of discovery, growth and responsibility in an unfamiliar, transformative world?'33

An analysis of five classic children's stories revealed five key narrative stages: indulgence, risk, separation and reunion, awareness, frame and return. While the act of listing out these phases suggests a linear sequence, many of these phases overlap. Indulgence - the promise of a fantastical experience - is what motivates the protagonist to undertake risk. It is within this stage that they begin to develop their sense of self. Separation is the protagonist's desire to assert independence from the family unit and transformative lessons - opportunities to grow and attain awareness - must be learnt before reunion can occur. ${ }^{34}$ The frame occurs concurrently with the reunion, its role is to:

affirm the work's therapeutic effects on both protagonist and reader: the reader's vision is cleansed, just as Alice awakens with her former 'inner restlessness' assuaged and with a renewed perception of 'what is necessary to happiness. ${ }^{\prime 35}$

In creating this architectural proposition [designer one] is drawing on a kind of evidence: the therapeutic effects of bibliotherapy. Those who read regularly are reported to sleep better, experience lower levels of stress, higher self-esteem and lower rates of depression than non-readers. ${ }^{36}$ As the fiction writer Jeanette Winterson has suggested fiction is a medicine that heal[s] the rupture reality makes on the imagination. ${ }^{37}$ While this is not a kind of evidence recognised within the evidence based design paradigm, [designer 1] identified it as relevant nonetheless and asked 'whether the healing made possible by leafing through the pages of children's stories could be delivered by traversing the paediatric hospital?'38

[place Fig. 1 about here]

[designer one] paired each narrative stage with a key hospital space. Indulgence relates to the entrance, risk to the waiting room, separation and reunion to the corridor, awareness to the treatment room, and frame and return to the patient room. This project recognises that an entrance is a first impression. It conveys implicit instructions for behaviour. It sets expectations for what will follow. [designer one] rejected a simple point of arrival, eschewing the typical threshold that instantly divides the normality of the world outside from the distinctiveness of a hospital interior. Her design offered a gradual process of arriving. The 'Fable Hospital' offers a whimsical entrance with an architectural backdrop reminiscent of a film set from Chitty Chitty 
Bang Bang (Fig. 1). Here the experience of entering the hospital is reconceptualised. It seeks to draw parallels with the sense of awe Charlie must have felt entering Wonka's Chocolate Factory and the challenges that Christopher Robin faced in the adult-free zone of the Hundred Acre Wood. ${ }^{39}$

Emergency physician Keith Joe has posited the techniques of electronic gaming as a tool for mitigating a child's fear of the hospital, suggesting a system of navigational and informational tasks and rewards as they progress through their visit. ${ }^{40}$ [designer one] sought, conversely, to embed this logic within the architecture itself. At the patient's first point of engagement with the hospital fields of wild flowers are offered up while butterflies circle windmills from another era. These are reimagined as 'seed towers' whose evening scatterings result in a carpet of 'richly scented flowers'. This is a space of indulgence, a chaotic mess of 'crushed, picked and whole flowers in varying stages of growth and decay', that patients traverse before moving through a shrinking series of brick arches that create an entrance tunnel. [designer one] offers an account of the intended arrival experience:

A height datum laps the edges of the tunnel, made by the scribbles and markings of hundreds of children who have passed through it before. Most children do not hesitate to contribute to the patina of graffiti. By the time patrons reach the door the arches have shrunk dramatically so that adults almost have to stoop, or is it that you [the patient] has grown bigger? ${ }^{41}$

\section{[place Fig. 2 about here]}

The entrance to 'Neverland' poses a similar challenge to convention. [designer two's] project was an attempt to test the limits of 'patient-centred design' by asking what a truly child-centred hospital would look like? Instead of beginning with a hospital and inserting distractions such as playgrounds, movie theatres or fish tanks, as per the prevailing approach to contemporary hospital design, [designer two] began with the infrastructure of the fairground. He used this to reimagine the functions of the hospital. A patient enters and is delivered to their next destination via a four storey carousel (Fig. 2), consultations are received within the gondola of a Ferris wheel and hospital corridors are replaced by crawl-space tunnels, sized to exclude adults. But distraction was not the only goal here, [designer two] sought to tackle the more serious question of whether architecture could be employed to redress the social isolation of children during illness, particularly chronic, by bringing healthy children into the hospital space via a shared interest in the environment itself.

[designer two's] project draws on anecdotal understandings that, generally, kids tend to like fairgrounds. This hints at the limitations of EBD in that the co-location of a 
fairground with a children's hospital has not been previously tested as a solution. While the limitations of this approach are readily identifiable, its potential affordances are completely unknown; the 'unanticipated breakthroughs' of this architectural proposition are unable to be predicted. This architectural proposition opens a line of questioning not dissimilar to the Maggie's Centres but instead of asking 'what if' it asks 'why not?' Why not a fairground, a movie set, a toy store, a water park, a museum of natural history? What are the rich opportunities for co-location (that might even extend to co-funding opportunities) that EBD dissuades from consideration?

While [designer two's] carousel suggests a more engaging way of arriving at and traversing the hospital, it also redefines expectations of what the process of waiting might entail. The waiting room itself is absent within the 'Neverland' project, as its function is assumed by the wider context of the fairground. This project responds to contemporary hospital practices that utilise the wide availability of mobile phones to free up patient movement during their visit. Patients at the Royal Children's Hospital (Melbourne, Australia), for example, can scan their appointment card on arrival and roam freely within a 10 minute radius of the outpatient clinic area. This enables them to enjoy the adjacent parkland and playgrounds relaxed in the knowledge that they will receive a text message reminding them to return in time for their appointment. The idea is to mitigate the agitation that arises from waiting and can be exacerbated by clinics running behind schedule.

\section{[place Fig. 3 about here]}

Similarly, the waiting space within 'The Fable Hospital' seeks to make positive use of this time by offering a physical distraction to alleviate anxiety. Poised far above the London skyline, and captivatingly retitled 'A System to Lift the Spirits' (Fig. 3), [designer one's] waiting room takes the form of a crystalline glass box with a high tech steel structure:

Upon registering at reception an estimated wait time will be assigned ... Then you have a choice. Two opposite routes; one direct, the other meandering, lead to the waiting room. A series of high speed lifts bolt straight to and from the waiting room and treatment areas. If a long wait time and physical capacity allow, a cantilevered network of stairs allow you to climb precariously to the top. Like a hiking trail in the sky, these can be used as a means of burning off excess energy and anxiety. Each stair is marked with the difficulty level and time taken to ascend it. ${ }^{42}$

Within both speculative projects the process of arrival and waiting are blurred through a gradual process of arriving and the provision of a physical experience not normally 
associated with the hospital environment. Both schemes provide escapism through distraction but additionally, through the increased temporal duration of the arrival process, a time for adjustment - for preparation and reorientation to this unfamiliar environment.

Parallels can be drawn between the strategy taken by [designer one] and that which Maurice Sendak employed within his children's books whereby adult themes, including 'rage, terror, death, abandonment [and] loss' were embedded but 'hidden in a world of wild things and sailboats and shaggy dogs. ${ }^{\prime 43}$ The borrowing of Sendak's Where the Wild Things Are as inspiration for 'The Fable Hospital' is fitting in light of the author's own experiences of sickness as a child, and the themes his work plays with as a result. Sendak recalled knowing 'terrible things' as a child, and knowing that he 'mustn't let adults know ... [what he] knew. ${ }^{\prime 44}$ [designer one's] proposition is an entreaty 'not to patronise children by obscuring hospital experiences beneath a veil of brightly coloured cartoon-like characters.' ${ }^{45}$ She advocates for a more honest approach that acknowledges the paediatric hospital as a site of discovery, growth and transformation, and translates this into a set of architectural strategies for reimagining the atmospheric qualities of these spaces. Correspondingly, the moments of distraction [designer one] offers within her waiting space are architectural. Window boxes descend below the floor, offering an experience not dissimilar to lingering along the edges of the Eiffel Tower, recasting the city below as a distant reality. Her project recognises that hospital spaces are infused with anxiety and the possibility of competing futures. To occupy a waiting room is to occupy a precipice because, once obtained, knowledge cannot be unlearned, no matter how life altering that knowledge might be.

[designer one's] project illuminates the question of who is protecting who beneath the decorative guise typically applied to hospital interiors. Roiphe has recounted a story that Sendak liked to tell of a child who witnessed the World Trade Centre Collapse:

She told her father that she saw butterflies on the building as the towers collapsed. Later she admitted ... they were people jumping, but she didn't want to upset her father by letting him know that she knew. ${ }^{46}$

[designer one] rejected decorative strategies aimed at obscuring the truth; advocating instead that designers articulate the functions of hospital spaces in a playful but honest manner. Scale, rhythm, materiality, light, technology, composition and texture are prioritised. Within the surgical theatre, for example, the ceiling displays a matrix of oversized pipework, a mix of shinny copper and painted red and white stripes. While this composition evokes recollections of Astrid Lindgren's Pippi Longstocking or Dr. Seuss' Cat in the Hat it is a spatial and functional composition. Although oversized, 
the pipes carry essential services while the large, retractable arms support theatre lights. To counter this honesty, giant planter boxes are placed beyond the windows of the theatre. The view of the patient, from pillow level looking upward, is prioritised within this space. As they drift off under the effects of anaesthetic their visual experience is intended to mimic that of sitting in a tree house peeking through the leaves at the world beyond (Fig. 4).

\section{[place Fig. 4 about here]}

Dunne and Raby have suggested that the challenge of speculative design is to 'blur the boundaries ... so that the conceptual becomes more real and the real is seen as just one limited possibility among many'. ${ }^{47}$ In this regard [designer two's] project provides a challenging spectrum for contemplation. His roller coaster enabled CT scanner, for example, irrefutably stretches the bounds of plausibility. That children could obtain diagnostic scans at high speed in a vehicle reminiscent of a Star Wars 'ARC-170 Star fighter' is compelling. But the obstacles to re-engineering two tonnes of carefully calibrated medical technology, whose current operational practices require a solid concrete enclosure, places this idea squarely in the realm of fantasy. Yet [designer two's] speculation provokes interesting questions: if roboticists are invested in the idea of the 'doctorless hospital' ${ }^{48}$ why not a hospital circulation system that operates via carousel? And if 3D-printed body parts are now a reality for transplantation ${ }^{49}$ what would stand in the way of prototyping a Ferris wheel enabled consulting room (Fig. 5)? This becomes more believable within the current healthcare climate where increasing percentages of the philanthropic donations made to paediatric hospitals are specified for features that can render this experience less hospital-like. These can include movie theatres, animal enclosures and Philips' Kitten-scanners (a miniature MRI scanner for toy animals to educate patients about the procedure and put them at ease). ${ }^{50}$ The price tags associated with these features are not insignificant.

\section{[place Fig. 5 about here]}

\section{Discussion}

The value proposition of speculative design is that it provokes an exploration of alternative social, cultural, technical or economic values. In this instance, the paediatric hospital has been employed as a vehicle for appraising this value proposition relative to the design, construction and inhabitation of contemporary healthcare environments. What current practices do the speculative projects produced by [designer one] and [designer two] prompt us to reconsider and, 
ultimately, is what value is to be gained from rethinking current practice through a speculative lens?

For two decades the literature on paediatric hospital design has recommended normalising this experience by concealing medical equipment and creating a 'homely' atmosphere. ${ }^{51}$ 'The Fable Hospital' entices us to consider what dropping the charade of normality might entail and suggests solutions far more compelling than the contemporary strategies of colour, iconography and an attempted replication of domesticity. This project questions whether our unrealistic desire, as adults, to keep the unpleasantness of the hospital contained within an adult world is, in fact, counterproductive. While this particular question has not been asked within EBD, there is evidence to suggest that current approaches to the interior design of paediatric hospitals are less than ideal. A study by Birch, Curtis and James obtained children's opinions on the interior design of a hospital constructed in the United Kingdom in 2007. They concluded that within contemporary paediatric hospital design:

the image of the young child [...] is taken to be iconic of children in general... [this is] something from which older children wish to disassociate themselves ... the majority of children and young people over 7 years of age were acutely aware, and critical, of the babyishness of the surroundings. ${ }^{52}$

Similar findings are reflected in other British and American studies. ${ }^{53}$ While [designer one's] 'Fable Hospital' provides multiple opportunities for imaginative escape that are indulgent and whimsical, they never render dishonestly the challenging and uncomfortable experiences that characterise this environment.

Within the occupiable space of the hospital - that occurs between shiny linoleum floors, walls (however brightly painted or tiled) and banally gridded ceilings - hope, anxiety, relief and despair permeate. These architectural speculations recognise and challenge the approach of offering fairly ordinary environments for life experiences that are far from quotidian. Both schemes attempt to displace health related fears by offering an encounter with physical danger, be that real or perceived. [designer one]'s 'System to Lift the Spirits', with its implausibly tall and delicate steel structure, drawn not quite level on the page, compounds the risk of dwelling within a space that is teetering just a touch precariously. [designer two]'s reimagining of procedural spaces goes further in requiring patients to face an exhilarating rollercoaster ride ahead of facing their results. These works give equal opportunity to the imaginative occupation of space, contesting the supremacy of the physical reality of the hospital. This approach recalls literary works such as Frame's Faces in the Water. Drawing on her experiences as a patient, at New Zealand's Seacliff Asylum in the 1940s, Frame wrote: 
Ward two was raised several feet above the ground on wood and stone stilts like a boathouse which must be kept beyond reach of the tide; I was ever conscious of a wavelike motion of the floor ... On the day that I really believed what they had been telling me ... that I would be in hospital for the rest of my life, the floor of the day room seemed to change to layers of shifting jagged slate that cut into my feet ... the sea gushed and slapped and the reek of salt was carried through the slates... ${ }^{54}$

The hospital Frame referenced was located high above the coastline. The 'reek of salt' was unlikely at best, there was no sea to gush and slap, and there was most certainly not a 'shifting jagged' floor. This detail becomes irrelevant, however, because the reader can intuitively understand that any accurate description of this hospital space - of its wall colours, curtains or floor boards - would be so completely inadequate in respect of the extraordinary situation in which Frame found herself. In taking a radical approach [designer one] and [designer two's] architectural speculations issue a challenge to contemporary hospital designers to consider how these environments might better attempt to match the emotional intensities that can accompany a hospital visit. How these environments might better respond to the point that Littlefield has made, that:

All buildings are, more or less, psychological entities ... skeletons on which we hang notions of self, society, status, heritage, value ... buildings live most powerfully in the mind and we constantly process them, assimilate them and digest them ... We constantly invest buildings with meaning. ${ }^{55}$

[designer two's] proposition issues another important challenge to EBD, that the built environment of the hospital may be capable of offering more to alleviate the social isolation experienced by patients with chronic illnesses. It prompts designers to ask if there are other (perhaps more realisable) strategies for bringing healthy children into this environment and whether this might offer valuable social or educational experiences, both for patients and healthy children. More broadly, both projects question how the experience of the hospital and the expectations patients bring to this space can be redefined by borrowing strategies from different contexts: the fairground or the narrative sequences of children's literature. Both approaches expand contemporary notions of how distraction is, and might be, provided within paediatric hospitals to alleviate the anxiety of patients. They prompt us to consider how much risk would actually be involved in taking a bolder approach?

Both projects reveal limitations in contemporary EBD practice. [designer one's] adoption of bibliotherapy as a therapeutic strategy questions the already ingrained disciplinary practices of recognising very particular types of evidence. It implores designers to embrace interdisciplinarity in order to find new directions for hospital 
architecture that may be capable of contributing solutions to the more complex questions of inhabiting these settings. In suggesting that greater attention be paid to the opportunities for colocation, [designer two] highlights perhaps the most important limitation of EBD: its uncomfortable fit with innovation. Innovation can fail and failure can be costly. There is little room within the EBD paradigm, with its dedication to proven solutions and the economic imperatives that quite rightly underpin this, to embrace failure. Yet Gorman and Patten have concurred that the ability to 'fail cheaply' is a necessary ingredient for innovation. ${ }^{56}$ In providing a research method that enables a low risk, low cost prototyping of ideas that may be radical, provocative or confounding, speculative design is a valuable counterpoint to accepted EBD research methods to advance design practice within contemporary healthcare environments.

\section{Conclusion}

Innovation is aided by strategies that enable the affordances and limitations of certain practices, both of research and design, to be challenged. Speculative design provides a methodology for projecting forward, to imagine new possibilities and alternative futures for the role and experience of the hospital. This complements the research methods currently employed within EBD that, owing to their reliance on built solutions whose benefits can be measured and thus proven, limits the capacity for innovation in the design of healthcare environments. As a design based research method, speculative design places a high value on the incorporation of knowledge from across disciplines and on prototyping solutions that boldly confront accepted design practice. Failure is now recognised as prerequisite for innovation. Speculative design enables the capacity to embrace failure within an economic reality that would ordinarily disallow it. It offers a low cost, low risk research method for the exploration of alternative solutions that would otherwise remain unthinkable within the context of hospital construction. As a form of design research, speculative design allows multiple possibilities to coexist and, as a research methodology, is itself just one of many possibilities. In our efforts to understand the relationship between the built environment and wellbeing a broader, more inclusive approach is required; one that recognises the unique value proposition offered by speculative design as complementary to the methods currently employed within EBD.

\footnotetext{
${ }^{1}$ See, for example: Diette, G.B., Lechtzin, N., Haponick, E., Devrotes, A. \& Rubin, H. Distraction Therapy with nature sights and sounds reduces pain during flexible bronchoscopy: A complementary approach to routine analgesia. Chest Journal 2003; 3: 941-948; Kain, Z.N., Mayes, L.C., CaldwellAndrews, A.A., Karas, D.E., \& McClain, B.E. Preoperative anxiety, postoperative pain and behavioral recovery in young children undergoing surgery. Pediatrics, 2006: 2; 651-658; Smith, A.M., Ortiguera,
} 
S.A., Laskowski, E.R. \& Hartman, A.D. A preliminary analysis of psychophysiological variables and nursing performance in situations of increasing criticality. Mayo Clinic Proceedings, 2001: 3; 275-84.

${ }^{2}$ Savransky, M., Rosengarten, M. What is nature capable of? Evidence, ontology and speculative medical humanities. Medical Humanities, 2016; 42: 166-72.

${ }^{3}$ Markauskaite, L., Goodyear, P., Epistemic Fluency and Professional Education: Innovation, Knowledgeable Action and Actionable Knowledge. Springer: 2016.

${ }^{4}$ Ulrich, R. View Through a Window May Influence Recovery. Science, 1984; 224: 224-225; Centre for Health Design. About us. https://www.healthdesign.org/about-us Accessed: 12 January 2017.

${ }^{5}$ See, for example: Gray, A.W., Kestern, K.S., Hurst, S., Anderko. L. Using Clinical Simulation Centers to Test Design Interventions: A Pilot Study of Lighting and Color Modifications. Health Environments Research and Design Journal 2012; 5: 46-65.

${ }^{6}$ Publication by author (details removed): Health Environments Research and Design Journal (in press).

${ }^{7}$ Nelson-Shulman, Y. Information and environmental stress: Report of a hospital intervention. Journal of Environmental Systems, 1984; 13: 303-316; Pati, D., Harvey T.E., Willis, D.A., Pati, S. (2015). Identifying elements of the health care environment that contribute to wayfinding. Health Environments Research \& Design Journal, 2015; 8: 44-67.

${ }^{8}$ Bennis, W.G., O’Toole , J. How Business Schools Lost their Way. Harvard Business Review, 2005; 83: 96-104.

${ }^{9}$ Publication by author (details removed): Health Environments Research and Design Journal (in press).

${ }^{10}$ Curtis, P., Northcott, A. The impact of single and shared rooms on family centered care in children's hospitals. Journal of Clinical Nursing, 2006; 26: 1584-1596; Maben, J., P. Griffiths, C. Penfold, M. Simon, E. Pizzo, J. Anderson, G. Robert, J. Hughes, T. Murrells, S. Brearley, J. Barlow. Evaluating a major innovation in hospital design: workforce implications and impact on patient and staff experiences of all single room hospital accommodation. Health Services and Delivery, 2015; 3.

${ }^{11}$ Sinclair, M., N.M. Ashkanasy, N.M. Intuition: Myth or Decision-Making Tool? Management Learning, 2005; 36: 353-370; Khatri, N., Ng, H.A. The role of intuition in strategic decision making. Human relations , 2000; 53: 57-86.

${ }^{12}$ Becker, F., Sweeny, B., Parsons, K. Ambulatory Facility Design and Patients Perceptions of Healthcare Quality. Health Environments Research and Design Journal , 2008; 4: 35-54; Muhlbauer, B.H. The 'Added Value' of Good Hospital Architecture for Personnel - An Economic Perspective. In Nickl-Weller, N., Nickl, H. (Eds.) Healing Architecture. Schweiz: Braun Publishing, 2013: 206-222.

13 Ulrich. 1984.

${ }^{14}$ Becker, F., Sweeny, B., Parsons, K. 2008.

${ }^{15}$ Dunne, A, Raby, F. Design Noir: The Secret Life of Electronic Objects. Berlin: Birkhauser, 2001.

${ }^{16}$ Dunne, A, Raby, F. 2001.

17 DiSalvo, C. Design and the Construction of Publics. Design Issues 2009; 25: 48-63.

${ }^{18}$ Savransky, M. Rosengarten, M. 2016.

${ }^{19}$ Edelson, D.C. Design research: what we learn when we engage in design. The Journal of Learning Sciences 2002; 11: 105-21.

${ }^{20}$ Edelson, D.C. 2002.

${ }^{21}$ For a discussion on Bill Burnett and Dave Evans ideas on prototyping refer: "Hidden Brain, Episode 56: Getting Unstuck [Design thinking for your life]" (podcast), 03 January 2017, http://www.npr.org/podcasts/510308/hidden-brain Date accessed 01 March 2017.

${ }^{22}$ Edelson, D.C. 2002.

${ }^{23}$ Dunne, D, Martin, R. Design thinking and how it will change management education: An interview and discussion. Academy of Management Learning \& Education 2006; 5: 512-523.

${ }^{24}$ Dunne, D, Martin, R. 2006. 
${ }^{25}$ Dunne, D, Martin, R. 2006.

${ }^{26}$ Henderson, M. Politics clouds blue-sky science. The Times. 19 September 2005.

${ }^{27}$ St Hill, C. Pile of hope - 20 years of Maggie's Centres. Design Crucial 2015. http://www.designcurial.com/news/pile-of-hope-4481924/ Date accessed: March 2016.

${ }^{28}$ Maggie Keswick Jencks Cancer Caring Centres Trust. Architectural Brief: Maggie's Centres, 2015. https://www.Maggie'scentres.org/media/uploads/file upload_plugin/Maggie's-architecturalbrief/architectural brief Maggie's.pdf Date accessed October 2015.

${ }^{29}$ Publication by author (details removed).

${ }^{30}$ Kain, Z,N, Mayes, L,C, Caldwell- Andrews, A,A, Karas, D,E, \& McClain, B,E. Preoperative anxiety, postoperative pain and behavioral recovery in young children undergoing surgery. Pediatrics 2006; 2: 651-658.

${ }^{31}$ [designer two] borrowed his project title 'Neverland' from the fictional location that featured in J.M Barrie's Peter Pan.

${ }^{32}$ Sadler, B.L, Berry, L.L., Guenther, R. Fable Hospital 2.0. Healthcare Design, 01 April 2011. http://www.healthcaredesignmagazine.com/article/fable-hospital-20 Date accessed 15 July 2016.

${ }^{33}$ [designer one]. The Fable Hospital. Design journal (unpublished), submitted in support of the design proposal for the Master of Architecture, 2016.

${ }^{34}$ Nodelman, P. Pleasure and Genre: Speculations on the Characteristics of Children's Fiction. Children's Literature, 2000; 28: 1-14.

${ }^{35}$ [designer one]. 2016. Note: [designer one] is drawing on the work of Gilead, S. Magic abjured: Closure in children's fantasy fiction. Publications of the Modern Language Association of America, 1991; 106: 277-293.

${ }^{36}$ Dovey C. Can reading make you happier. New Yorker. 09 June 2015. http://www.newyorker.com/culture/cultural-comment/can-reading-make-you-happier Date accessed: 12 May 2016. Also refer: Fujiwara, D. Lawton R., Mourato,S. The health and wellbeing benefits of public libraries, 2015. http://www.artscouncil.org.uk/sites/default/files/downloadfile/The\%20health\%20and\%20wellbeing\%20benefits\%20of\%20public\%20libraries.pdf Date accessed: 12 May 2016.

${ }^{37}$ Winterson, J. Why be happy when you could be normal? New York: Grove Press, 2012.

${ }^{38}$ [designer one]. 2016.

39 [designer one's] project was informed by J.M. Barrie's Peter Pan, Lewis Carroll's Alice's Adventures in Wonderland, Roald Dahl's Charlie and the Chocolate Factory and Maurice Sendak's Where the Wild Things Are.

${ }^{40} \mathrm{Joe}, \mathrm{K}$. Using Electronic Game Techniques to Create Better Hospital Experiences. TEDxMelbourne, 14 January 2014. https://www.youtube.com/watch?v=VllplnQ4v7l Date accessed: January 2016.

${ }^{41}$ [designer one]. 2016.

42 [designer one]. 2016.

${ }^{43}$ Roiphe, K. The Violet Hour: Great Writers at the End. London: Virago Press, 2016.

${ }^{44}$ Sendak cited within Roiphe, 2016.

${ }^{45}$ [designer one]. 2016.

${ }^{46}$ Sendak cited within Roiphe, 2016.

${ }^{47}$ Dunne, A, Raby, F. 2001.

${ }^{48}$ Jaiprakash, A., Roberts, J., Crawford, R. Robots in healthcare could lead to a doctorless hospital. The Conversation, 09 February 2016. http://theconversation.com/robots-in-health-care-could-lead-to-a-doctorless-hospital-54316 Date accessed: April 2017.

${ }^{49}$ Bowen, N. Anatomics: The Neurosurgeon's Bone Factory, Australia Unlimited, 28 January 2016. http://www.australiaunlimited.com/technology/the-neurosurgeon-s-bone-factory Date accessed: April 2017. 
${ }^{50}$ Philips Design. KittenScanner: involving kids in their own care. https://www.90yearsofdesign.philips.com/article/30 Date accessed: November 2016.

${ }^{51}$ Nanda, U., Pati, D., Ghamari, H., Bajema, R. Lessons from Neuroscience: Form follows function, emotions follow form. Intelligent Buildings International 2013; 5 : 61-78.

${ }^{52}$ Birch, J., Curtis, P., James, A. 2007.

${ }^{53}$ Clift, L., Dampier, S., Timmons, S. 'Adolescents' experiences of emergency admission to children's wards. Journal of Child Healthcare 2007; 11: 195-207; Tivorsak, T., Britto, M., Klosterman, B., Nebrig, D., Slap, G. Are pediatric settings adolescent friendly? an exploration of attitudes and preferences. Clinical Pediatrics 2004; 43: 55-61.

${ }^{54}$ Frame, J. Faces in the Water. Christchurch: Pegasus Press, 1961.

${ }^{55}$ Littlefield, D. Introduction. In D. Littlefield, Lewis S. (Eds.) Architectural Voices: Listening to Old Buildings. West Sussex: Wiley-Academy, 2009: 1-9.

${ }^{56}$ Gorman, M.J. Crucibles of Creativity. Public lecture, University of Melbourne, 25 August 2015. https://www.carltonconnect.com.au/watch-crucibles-of-creativity-with-michael-john-gorman/ Accessed: 18 May 2017; Patten, J. Challenging the Audience to Work in Anti-Disciplinary Spaces. Lift Conference, 07 April 2016. http://opentranscripts.org/transcript/challenging-audience-

antidisciplinary-spaces/ Accessed 07 March 2017. 


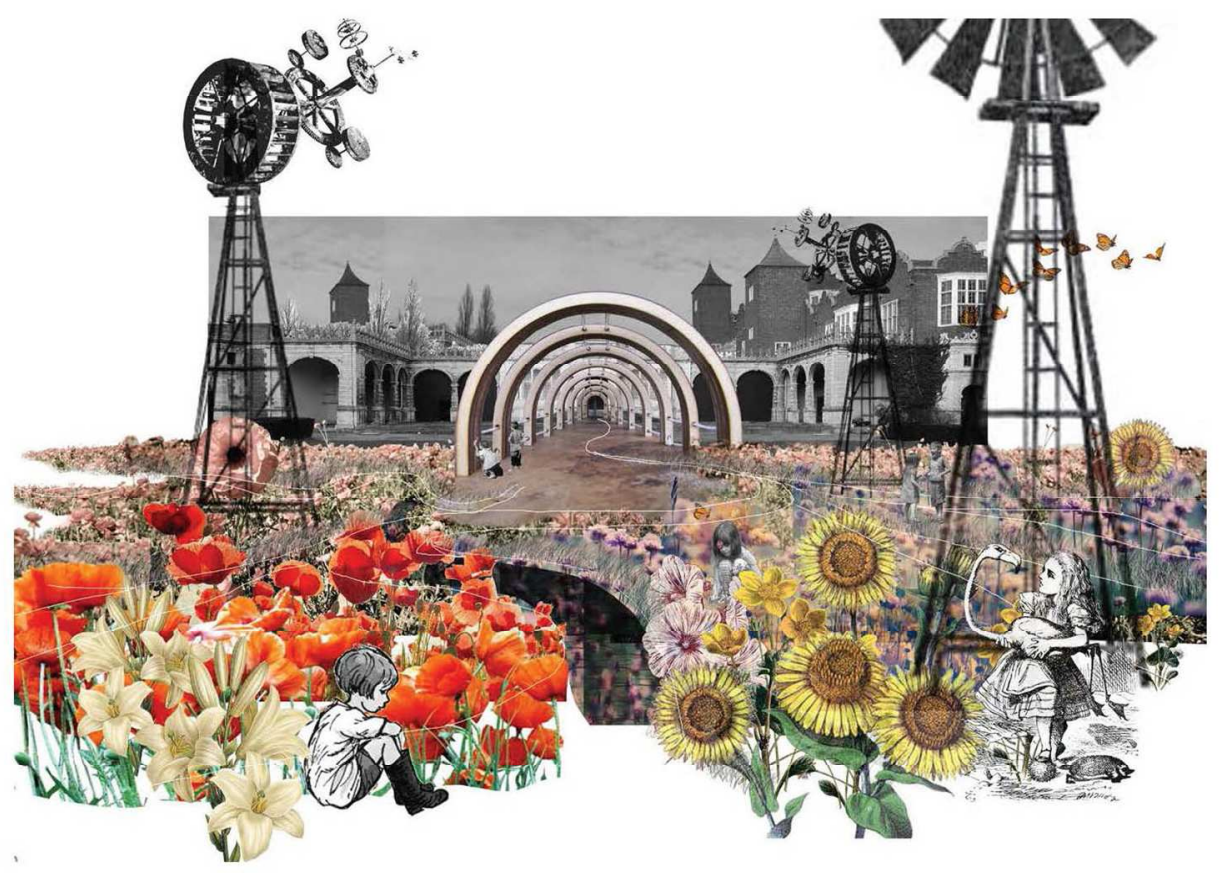

Entrance garden and tunnel, the Fable Hospital, [designer one], 2016. $255 \times 183 \mathrm{~mm}(150 \times 150 \mathrm{DPI})$ 


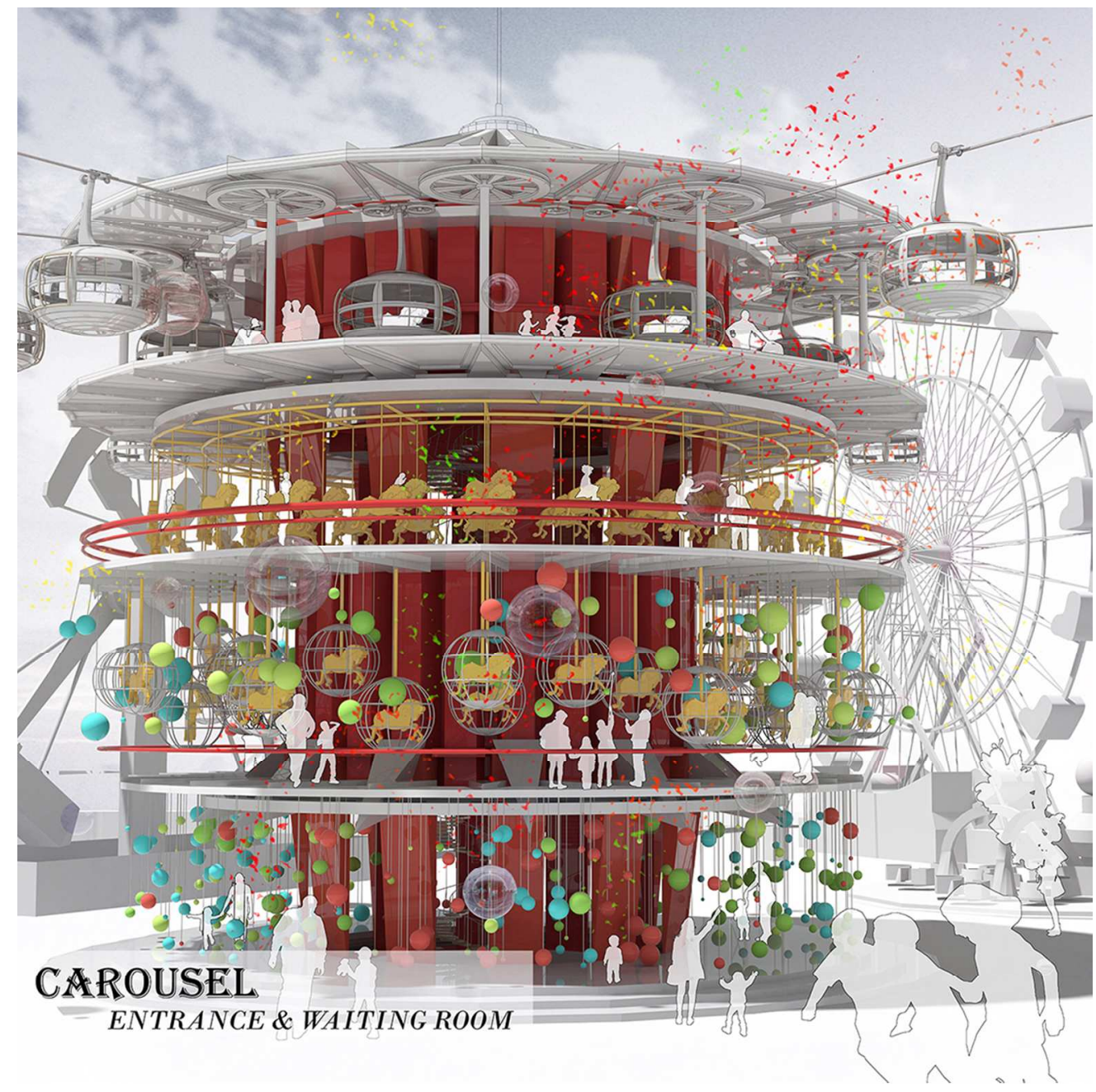

Entrance carousel, Neverland, [designer two], 2016. $139 \times 139 \mathrm{~mm}(200 \times 200$ DPI $)$ 


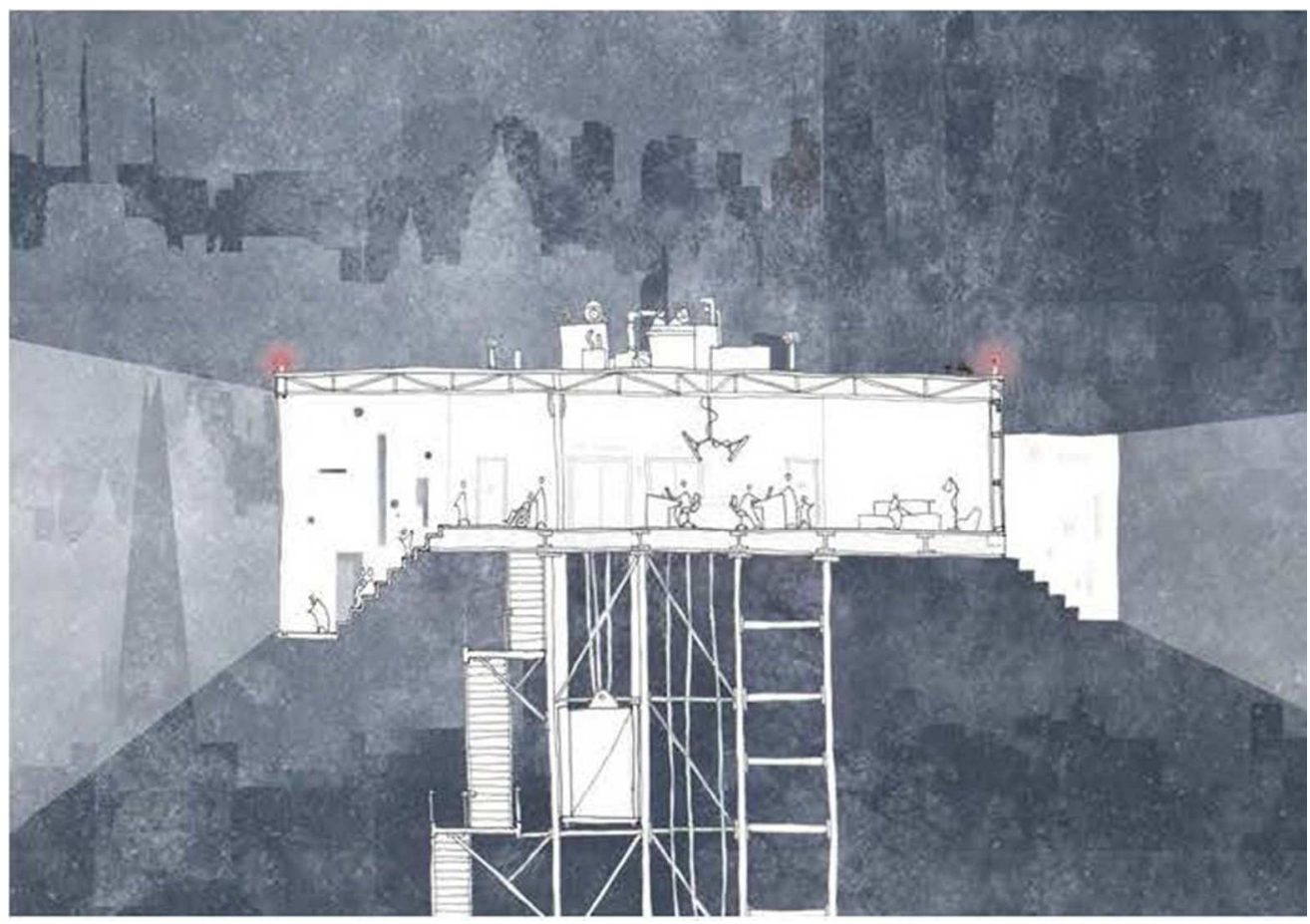

A System to Lift the Spirits (the waiting room), section drawing, the Fable Hospital, [designer one], 2016. $115 \times 81 \mathrm{~mm}(150 \times 150 \mathrm{DPI})$ 


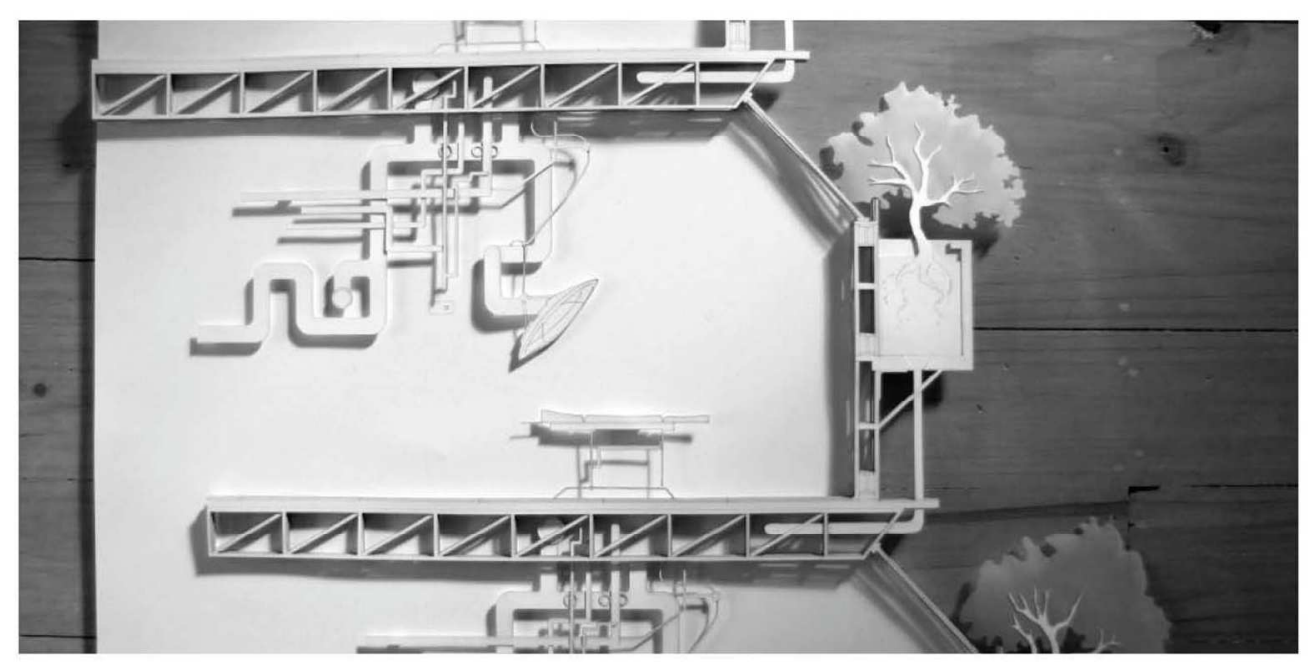

Surgical space, 3D laser-cut section drawing, the Fable Hospital, [designer one], 2016. $241 \times 123 \mathrm{~mm}(150 \times 150 \mathrm{DPI})$ 


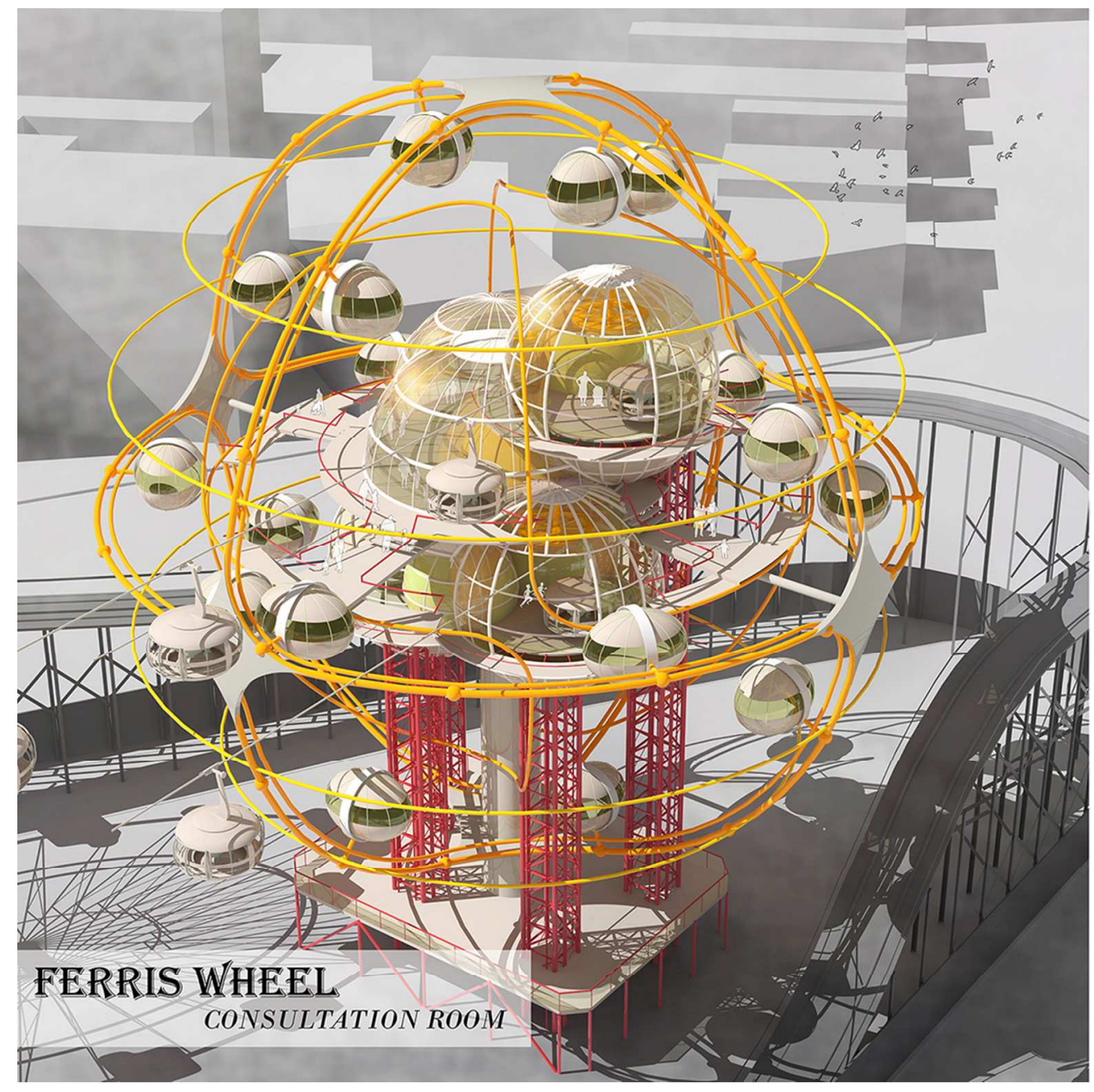

Ferris wheel consultation room, Neverland, [designer two], 2016. $139 \times 139 \mathrm{~mm}(200 \times 200 \mathrm{DPI})$ 